\title{
Short communication: Informative value of an ELISA applied to bulk tank milk to assess within-herd prevalence of digital dermatitis in dairy herds
}

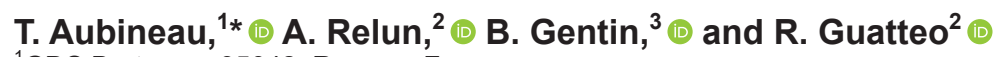 \\ ${ }^{1}$ GDS Bretagne, 35042, Rennes, France \\ ${ }^{2} \mathrm{BIOEPAR}$, INRAE, Oniris, 44307, Nantes, France \\ ${ }^{3}$ BIOSELLAL, 69000, Dardilly, France
}

\section{ABSTRACT}

The objective of this study was to assess whether an antibody ELISA applied to bulk tank milk (BTM) could be used to accurately estimate within-herd prevalence of digital dermatitis (DD). The ELISA was designed for the detection of antibodies against Treponema phagedenis-like strain V1 (PrrA antigen). The hind feet of all lactating cows from 40 commercial French dairy herds with a history of DD were scored by an observer in the milking parlor, using the $4 \mathrm{M}$-stage system. After milking, a BTM sample was collected and tested for anti-Treponema phagedenis-like antibodies using the antibody ELISA. Within-herd DD prevalence at the cow level was determined using 2 different approaches: (1) having DD lesion on at least 1 hind foot (Prev; prevalence of affected cows), and (2) having an M1 or M2 lesion on at least 1 hind foot (PrevA; prevalence of cows affected by DD in an active stage). Receiver operating characteristic analysis was used to determine both optimal within-herd DD prevalence and BTM sample to positive $(\mathrm{S} / \mathrm{P})$ ratio cut-off values. Two optimal cut-off values were identified. Herds with an S/P ratio of BTM $\leq 0.2$ had a Prev $\leq 10 \%$ (sensitivity = 0.97 , specificity $=1$ ), whereas herds with an $\mathrm{S} / \mathrm{P}$ ratio of BTM $>0.38$ had a Prev $>40 \%$ (sensitivity $=0.94$, specificity $=0.86)$. In the same way but with a slightly lower specificity, an $\mathrm{S} / \mathrm{P}$ ratio $>0.38$ corresponds also to a PrevA $>18 \%$ (sensitivity $=0.92$, specificity $=0.70)$. The BTM antibody ELISA shows great promise for screening purposes during DD management programs. Key words: digital dermatitis, prevalence, ELISA, dairy herd

\section{Short Communication}

Lameness is a major welfare issue in dairy cattle (FVE, 2019). Digital dermatitis (DD) is the most

Received April 7, 2020.

Accepted August 13, 2020.

*Corresponding author: thomas.aubineau@gds-bretagne.fr common infectious cause of lameness in dairy herds, occurring in 70 to $96 \%$ of herds in several countries (Holzhauer et al., 2006; Cramer et al., 2008; Solano et al., 2016). The within-herd prevalence is highly variable, ranging from 0 to $83 \%$ of cows affected in extreme cases (Rodriguez-Lainz et al., 1998; Holzhauer et al., 2006; Cramer et al., 2008). In affected herds, the control of DD relies on multimodal strategies that combine improvements in cattle hygiene and comfort, early detection and treatment of cows affected by DD, and regular foot bathing (Potterton et al., 2012; Cook, 2017; Oliveira et al., 2017a). Thus, the monitoring of within-herd prevalence of affected cows is crucial to describe the dynamics of infection and to adapt control strategies. The gold standard for the detection of DD lesions is the examination of feet in a trimming chute. Alternative methods based on examination of hind feet in the milking parlor using a swiveling mirror (Relun et al., 2011; Solano et al., 2017; Cramer et al., 2018), a borescope (Stokes et al., 2012; Ferraro et al., 2020), or without any specific tool (Rodriguez-Lainz et al., 1998; Thomsen et al., 2008) have been successfully tested. However, as these methods are dependent on observation conditions (Oliveira et al., 2017b; Yang and Laven, 2019) and some methods are time consuming, there is a need for alternatives.

Digital dermatitis lesions are of polymicrobial origin. However, the presence of spirochetes of the Treponema genus is recognized as a key component (Evans et al., 2008; Klitgaard et al., 2013; Krull et al., 2014). Among treponemes, Treponema phagedenis is isolated from 95 to $100 \%$ of biopsy samples from infected feet, whatever the stage of infection (Klitgaard et al., 2013). Thus, the putative interest of a blood ELISA based on Treponema antigens has already been investigated (Vink et al., 2009; Moe et al., 2010; Gomez et al., 2014). For instance, Gomez et al. (2014), using antigens from bacterial suspension of $T$. phagedenislike strains 1-9185MED and 2-1498, observed a $56 \%$ increase in IgG antibodies in heifers upon first diagnosis of an M2 stage and a gradual decrease in antibodies as heifers healed, reaching antibody levels 
of unaffected heifers after a mean of $223 \mathrm{~d}$. Using 4 different immunogenic proteins from T. phagedenislike strain V1 and purified as described by Rosander et al. (2011), Frössling et al. (2018) compared individual milk antibody titers between cows presumed unaffected (cows with good claw health from herds where DD had never been detected) and cows affected by DD. As they sought to get equal sensitivity and specificity, authors observed the best performances with the antigen PrrA, which can detect affected cows with a sensitivity and a specificity of $78 \%$, and a positive correlation between antibody levels in the bulk tank milk (BTM) and the presence of cows affected by DD in the herds (Frössling et al., 2018). However, Frössling et al. (2018) did not take the within-herd DD prevalence nor lesion stages into consideration. Yet, stage of DD lesion, as developed by Döpfer et al. (1997) and amended by Berry et al. (2012), is of key importance because it influences pain sensation (Frankena et al., 2009; Cutler et al., 2013) and infectivity (Döpfer et al., 2012; Biemans et al., 2018). In this way, knowing the within-herd prevalence of cows affected by active lesions, that is to say M1, M4.1 or M2 stage lesions as described by Biemans et al. (2018), could be helpful to adapt control strategies.

Therefore, the objective of this study was to identify optimal cut-offs and associated sensitivities and specificities of an antibody ELISA based on PrrA antigen applied to BTM to define within-herd prevalence classes, considering (1) the prevalence of affected cows at any stage of lesion and (2) the prevalence of cows affected by DD in an active stage, as defined by Biemans et al. (2018).

The study was conducted on 40 dairy farms with Holstein Friesian cattle in Brittany, France between January and April 2018. The number of herds selected was determined for practical and budgetary reasons. To assess this ELISA applied on BTM in a wide range of within-herd prevalence, herds were selected based on their prevalence of cows affected by DD lesions. A proxy of this prevalence was estimated during a previous trimming procedure on 20 cows (10 lame and 10 healthy) selected from each herd by a technician specialized in health advising. Lame and healthy cows were selected based on their gait score (Sprecher et al., 1997), considering a lame cow as a cow which stands with an arched-back posture or with a pain relief on at least 1 foot (scores $3-5$ ), and a healthy cow as a cow which stands with a level back posture (scores 1-2).

Herds were enrolled between 1 and 6 mo after trimming procedure. Each herd was visited once. The hind feet of all lactating cows were examined in the milking parlor during milking, according to the method described by Relun et al. (2011). In brief, feet were flushed with clean water with a medium pressure hose, inspected using a swiveling mirror and a powerful headlamp, and scored according to a $4 \mathrm{M}$-stage scoring system (M0, M1, M2, M4), where M1 comprises M1 and M4.1, and M4 comprises M3 and M4 lesions as described by Tremblay et al. (2016). This examination was carried out by the same inspector on the 40 farms. Before the start of the study, the inspector was trained by the corresponding author in the use of the M-stage scoring system with a panel of pictures of DD lesions from feet standing in the milking parlor, which included lesion stages from M0 to M4. Pictures were first used during 1 training session at the office and a second time during 2 training sessions in commercial farms where DD was endemic, in association with feet inspection of 117 lactating cows in the milking parlor.

During the same visit, a sample of BTM was collected after milking. To ensure the BTM sample was representative, the sampling was made at the end of the milking after mixing by automatic stirrer. The sample was taken through the upper opening using a 40-mL screw-cap tube containing $8 \mathrm{mg}$ of bronopol. Milk samples were transported to the laboratory under controlled temperature $\left(4^{\circ} \mathrm{C}\right)$ on the day of sampling, and then stored at $-20^{\circ} \mathrm{C}$ until analysis.

Each milk sample was tested using a ready to use indirect antibody ELISA kit (BioLisa kit Dermatitis Ab) developed by BIOSELLAL (Dardilly, FRANCE). The ELISA was set up with an immunogenic protein PrrA from the T. phagedenis-like strain V1. The recombinant protein was purified as described by Rosander et al. (2011). Microtiter plates were coated with the PrrA recombinant protein. The optimal antigen concentration was obtained by using a checkboard titration technic. Milk samples were tested during the same set of analysis after a 1:2 dilution directly in the reaction plate: $50 \mu \mathrm{L}$ of mixed milk $+50 \mu \mathrm{L}$ of dilution buffer. Samples were incubated at $37^{\circ} \mathrm{C}$ for $2 \mathrm{~h}$, and unbound proteins were removed by washing 3 times with $300 \mu \mathrm{L}$ of washing buffer. Plates were then incubated for $1 \mathrm{~h}$ at $37^{\circ} \mathrm{C}$ with $100 \mu \mathrm{L}$ of peroxidase-conjugated rabbit antibovine IgG polyclonal antibody (Sigma) diluted 1:100. After washing, TMB (3,3', 5,5'-tetramethylbenzidine) substrate $(100 \mu \mathrm{L} /$ well $)$ was added. After $10 \mathrm{~min}$ at room temperature in the dark, the reaction was stopped by adding $100 \mu \mathrm{L}$ of stop solution. Optical densities (OD) were measured at $450 \mathrm{~nm}$. Negative and positive control samples were tested for each analysis and used for interpreted value calculations. The origins of negative and positive control samples are described by Frössling et al. (2018). The interpreted sample to positive $(\mathbf{S} / \mathbf{P})$ ratios were calculated using the following formula: (sample OD - negative control OD)/(positive control OD - negative control OD). 
Next, the within-herd prevalence of affected cows was determined using 2 different classifications for an affected cow: (1) having a DD lesion on at least 1 hind foot (affected cow) and (2) having an M1 or M2 lesion on at least 1 hind foot (cow affected by DD in an active stage).

The within-herd prevalence of affected cows (Prev) and cows affected by DD in an active stage $(\operatorname{PrevA})$ were first described and compared. Then the correlation between within-herd prevalence and the $\mathrm{S} / \mathrm{P}$ ratios of the ELISA were studied, first by visual appraisal, and second by estimating and testing the Spearman linear correlation coefficient using the cor function from the $\mathrm{R}$ package stats ( $\mathrm{R}$ Core Team, 2018). Receiver operating characteristic analysis was used to identify both optimal within-herd DD prevalence and the bulk milk $\mathrm{S} / \mathrm{P}$ ratio cut-off value. First, the prevalence was made dichotomous; for each cut-off value incremented by $5 \%$ between 5 and $95 \%$, the ability of the ELISA to correctly classify herds was assessed by measuring the area under the curve (AUC). Only prevalence cut-offs for which the test had excellent accuracy, defined as AUC above 0.9 , were retained. Then, for each prevalence cutoff retained, the optimal $\mathrm{S} / \mathrm{P}$ ratio cut-off value was determined as those that maximized the Youden's index, to optimize both sensitivity and specificity. Finally, the corresponding positive and negative predictive values were calculated. The receiver operating characteristic analysis were performed using the ROC function from the $\mathrm{R}$ package Epi, and informative value were calculated using the epi.tests function from the $\mathrm{R}$ package epiR.

Herds included had between 35 and 126 lactating cows, with a mean of 79 lactating cows $(\mathrm{SD}=21.6)$. The average within-herd proportion of primiparous cows ranged from 11 to $50 \%$, with a mean of $32 \%$ (SD $=9.3 \%)$. The Prev ranged from 3 to $72 \%$, with a mean of $35 \%(\mathrm{SD}=19 \%)$, and PrevA ranged from 0 to $48 \%$, with a mean of $14 \%(\mathrm{SD}=10.5 \%)$. The correlation between Prev and PrevA was moderate $(\mathrm{r}=0.75)$, but different from $0(P<0.01)$.

The correlations between within-herd prevalence of affected cows and BTM S/P ratios were poor to moderate $(\mathrm{r}=0.7$ for Prev and $\mathrm{r}=0.5$ for PrevA, Figure 1$)$, but different from 0 ( $P<0.01$ for both). The accuracy results of BTM ELISA tests in relation to within-herd prevalence are summarized in Table 1. Concerning Prev, an AUC of more than 0.9 was obtained for 3 thresholds. Among them, the best results were achieved at a Prev threshold of $10 \%$, with an $\mathrm{S} / \mathrm{P}$ ratio cut-off at 0.2 (Youden index $=97 \%$, sensitivity $=97 \%$, and specificity $=100 \%$ ). Only 5 of the 40 herds obtained $\mathrm{S} / \mathrm{P}$ ratios below this cut-off. Very good accuracy was also achieved with a Prev threshold of $40 \%$, with an
$\mathrm{S} / \mathrm{P}$ ratio cut-off at 0.38 (Youden index $=81 \%$, sensitivity $=94 \%$, and specificity $=86 \%$ ). These 2 cut-off values are outlined in Figure 1. The positive and negative predictive values calculated in the study sample for the 3 Prev thresholds were high and ranged from 80 to $100 \%$, except for the negative predictive value at the threshold of $15 \%$, which was of $58 \%$ (Table 1 ). Concerning PrevA, none of the prevalence thresholds tested were associated with an AUC of more than 0.9. Despite this overall lack of accuracy, moderate results were achieved for a threshold of $18 \%$, with an $\mathrm{S} / \mathrm{P}$ ratio cut-off at 0.38 , as outlined in Table $1(\mathrm{AUC}=0.81$, Youden index $=63 \%$, sensitivity $=92 \%$, and specificity $=70 \%)$.

The results of this study show that the antibody ELISA designed to detect antibodies directed against the PrrA antigen of $T$. phagedenis, when applied to BTM, was able to discriminate between herds with low $(\leq 10 \%)$, medium (10-40\%), and high prevalence $(>40 \%)$ of cows affected by DD, at any the stage of the lesion. However, the test did not have sufficient performance to estimate prevalence of cows affected by DD in an active stage. The very wide range of within-herd prevalence in our study is in accordance with previous studies that estimate within-herd prevalence in a large number of herds (Rodriguez-Lainz et al., 1998; Holzhauer et al., 2006; Cramer et al., 2008), which makes it possible to assess variability of $\mathrm{S} / \mathrm{P}$ ratio for $\mathrm{BTM}$ ELISA.

The $\mathrm{S} / \mathrm{P}$ ratio results were better associated with Prev than with PrevA. Gomez et al. (2014) observed a $56 \%$ increase in IgG antibodies in heifers upon first diagnosis of an M2 stage, and a gradual decrease in antibodies as heifers healed to the M0 stage. This suggests that the number of antibodies in BTM depends on cows affected by DD in an active stage, cows affected by DD in a chronic stage, and recovered cows. In our study, the higher proportion of cows affected by DD in a chronic stage compared with cows affected by DD in an active stage may explain why the BTM ELISA results were more highly correlated with Prev. As chronic lesions considerably contribute to infectivity in the herd (Biemans et al., 2018), the BTM ELISA that we tested could be very useful to evaluate the risk of new infections in the herd. For instance, because of the very high sensitivity and specificity at the S/P ratio cut-off of 0.2, BTM ELISA could be particularly useful to identify herds with a very small proportion of infected cows and a low risk of new infections. This could be important information when a breeder wants to buy a cow. However, only 5 herds had a within-herd prevalence of less than $10 \%$ in our study. These results need to be confirmed in a higher number of herds, particularly in herds with low prevalence, to assess the 
specificity of the BTM ELISA at this cut-off with more accuracy and precision. Moreover, it could be interesting to assess the ability of the BTM ELISA to discriminate between DD-free herds and herds affected by DD at a low prevalence. In addition to the idea of testing BTM ELISA specificity, it could also be interesting to challenge this BTM ELISA by a high herd prevalence of udder cleft dermatitis. Indeed, even if T. phagedenislike seems not to be responsible for udder cleft lesions (Sobhy et al., 2020), it has been detected by PCR and immunohistochemistry from the udder cleft dermatitis lesions and healthy skin of udder cleft (Ekman, 2020).

The BTM ELISA accuracy, especially specificity, was only moderate at detecting herds with a within-herd $\mathrm{DD}$ prevalence of active lesions $>18 \%$ at the $\mathrm{S} / \mathrm{P}$ ratio cut-off of 0.38 . Consequently, among herds with a high risk of new infections (a high prevalence of cows affected, whatever the stage), the BTM ELISA could fail to discriminate with high accuracy between herds with a high or low prevalence of cows affected by DD in an active stage. Further studies should investigate the possibility of repeating the BTM ELISA at short time intervals to detect an increase in the prevalence of cows affected by DD in an active stage to help identify herds in which control strategies need to be strengthened or refined.

The indirect ELISA used in our study was set up with the immunogenic protein PrrA from the T. phagedenis-
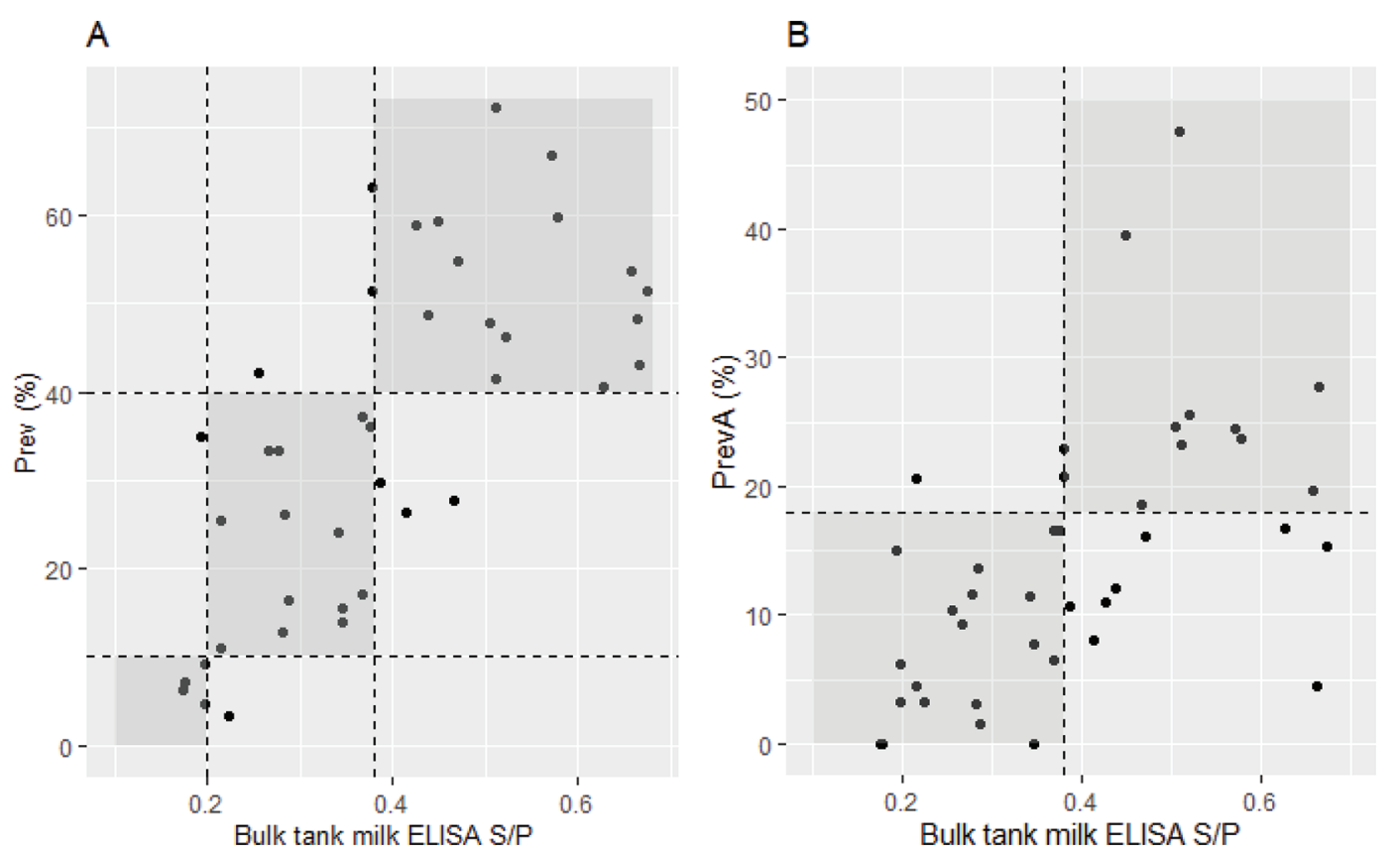

Figure 1. Correlation between bulk tank milk ELISA results as sample to positive (S/P) ratios and (A) within-herd prevalence of cows affected by digital dermatitis (DD) (Prev; every stage included) or (B) within-herd prevalence of cows affected by DD in an active stage (PrevA; only M1, M4.1 and M2 stages included), as described by Biemans et al. (2018). Dashed lines and gray rectangles delineate prevalence thresholds and $\mathrm{S} / \mathrm{P}$ cut-offs of interest outlined.

like strain V1. Even if T. phagedenis is one of the most highly isolated bacteria of the Treponema genus in DD lesions, it can be assumed that other Treponema species were present in some of the DD lesions observed. This may have induced a lack of sensitivity for the BTM ELISA when estimating prevalence. An indirect ELISA set up with immunogenic proteins from several species should be assessed to estimate the increase in sensitivity.

The study design did not consider cows which were not milked into the bulk tank, while every cow observed in the milking parlor was included in the within-herd prevalence calculation. However, as current DD treatments do not require a mandatory withdrawal period in the study geographical area, this induced bias should not have been selective (milk from cows with DD lesions was collected in bulk tank).

Lastly, the reference method used to score DD status, to which we compared the BTM ELISA results, is not the gold standard. Considering absence versus presence of a DD lesion on a foot, this method had a sensitivity of 0.9 and a specificity of 0.8 when it was compared with inspection of the feet in the trimming chute. But considering 4 M-stage scoring, $29 \%$ of DD lesions scored M2 at the inspection in the trimming chute were classified as M4 at the inspection in the milking parlor (Relun et al., 2011). This discrepancy could have produced a slight risk of misclassification 


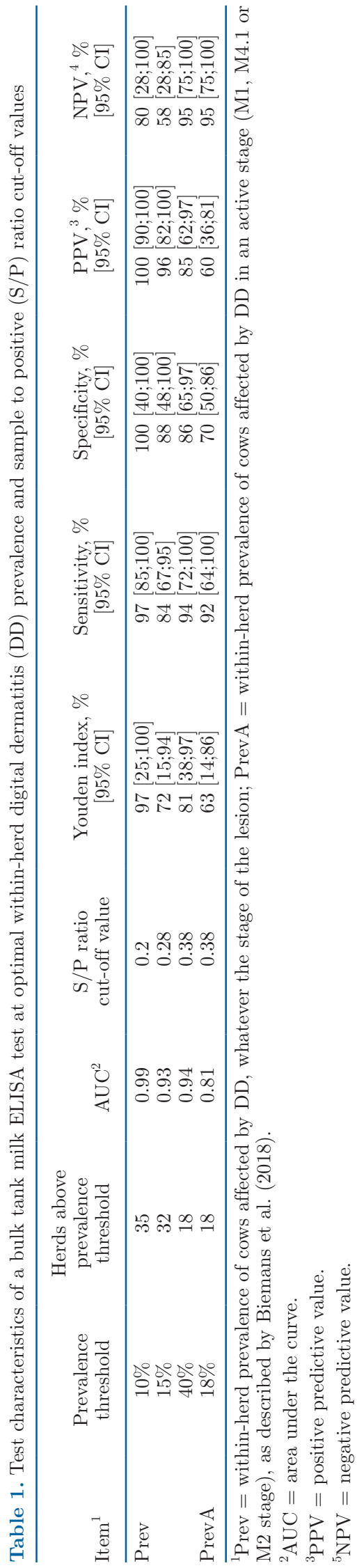

of herds regarding within-herd prevalence threshold in our study. More specifically, it could explain in part the lack of specificity of the BTM ELISA at the cut-off of 0.38 and for the PrevA threshold of $18 \%$. Inspection of the feet was conducted by the same observer in all herds included in the study. This excluded the risk of misclassification due to the moderate agreement of M-stage scoring between observers (Vanhoudt et al., 2019).

In conclusion, the BTM ELISA with the immunogenic protein PrrA from the T. phagedenis-like strain V1 could be useful to assess within-herd prevalence. It is a promising tool for screening purposes during DD control programs. Further investigations are needed to confirm our preliminary results in a larger number of herds, using DD scoring in a trimming chute as a reference method. Moreover, investigations should focus on the informative value of repeating the BTM ELISA to increase its performance.

\section{ACKNOWLEDGMENTS}

The authors sincerely acknowledge the 40 dairy producers who participate in this project, Ronan Fourgot and Audrey Hubert (Oniris, Nantes, France) for their contribution to data collection and analysis, Christèle Lucas (LABOCEA, Fougères, France) for her contribution to data collection, and Aurélien Madouasse and François Beaudeau (BIOEPAR, INRAE, Oniris, Nantes, France) for advice regarding statistical analysis. The authors thank BIOSELLAL (Dardilly, France) and GDS Bretagne (Rennes, France) for financial support of this project. The authors have not stated any conflicts of interest.

\section{REFERENCES}

Berry, S. L., D. H. Read, T. R. Famula, A. Mongini, and D. Döpfer. 2012. Long-term observations on the dynamics of bovine digital dermatitis lesions on a California dairy after topical treatment with lincomycin $\mathrm{HCl}$. Vet. J. 193:654-658. https://doi.org/10 $.1016 / j . t v j l .2012 .06 .048$.

Biemans, F., P. Bijma, N. M. Boots, and M. C. M. de Jong. 2018. Digital dermatitis in dairy cattle: The contribution of different disease classes to transmission. Epidemics 23:76-84. https://doi .org/10.1016/j.epidem.2017.12.007.

Cook, N. B. 2017. A review of the design and management of footbaths for dairy cattle. Vet. Clin. North Am. Food Anim. Pract. 33:195-225. https://doi.org/10.1016/j.cvfa.2017.02.004.

Cramer, G., K. D. Lissemore, C. L. Guard, K. E. Leslie, and D. F. Kelton. 2008. Herd- and cow-level prevalence of foot lesions in Ontario dairy cattle. J. Dairy Sci. 91:3888-3895. https://doi.org/ 10.3168/jds.2008-1135.

Cramer, G., T. Winders, L. Solano, and D. H. Kleinschmit. 2018. Evaluation of agreement among digital dermatitis scoring methods in the milking parlor, pen, and hoof trimming chute. J. Dairy Sci. 101:2406-2414. https://doi.org/10.3168/jds.2017-13755.

Cutler, J. H. H., G. Cramer, J. J. Walter, S. T. Millman, and D. F. Kelton. 2013. Randomized clinical trial of tetracycline hydrochlo- 
ride bandage and paste treatments for resolution of lesions and pain associated with digital dermatitis in dairy cattle. J. Dairy Sci. 96:7550-7557. https://doi.org/10.3168/jds.2012-6384.

Döpfer, D., M. Holzhauer, and M. van Boven. 2012. The dynamics of digital dermatitis in populations of dairy cattle: Model-based estimates of transition rates and implications for control. Vet. J. 193:648-653. https://doi.org/10.1016/j.tvjl.2012.06.047.

Döpfer, D., A. A. H. M. ter Huurne, J. L. Cornelisse, A. J. A. M. van Asten, A. Koopmans, F. A. Meijer, Y. H. Schukken, I. Szakall, W. Klee, and R. B. Bosma. 1997. Histological and bacteriological evaluation of digital dermatitis in cattle, with special reference to spirochaetes and Campylobacter faecalis. Vet. Rec. 140:620-623. https://doi.org/10.1136/vr.140.24.620.

Ekman, L. 2020. Udder cleft dermatitis in dairy cows. PhD Thesis. Department of Clinical Sciences, Swedish University of Agricultural Sciences, Uppsala, Sweden.

Evans, N. J., J. M. Brown, I. Demirkan, R. D. Murray, W. D. Vink, R. W. Blowey, C. A. Hart, and S. D. Carter. 2008. Three unique groups of spirochetes isolated from digital dermatitis lesions in UK cattle. Vet. Microbiol. 130:141-150. https://doi.org/10.1016/ j.vetmic.2007.12.019.

Ferraro, S., S. Buczinski, S. Dufour, M. Rousseau, J. Dubuc, J.-P. Roy, and A. Desrochers. 2020. Bayesian assessment of diagnostic accuracy of a commercial borescope and of trimming chute exams for diagnosing digital dermatitis in dairy cows. J. Dairy Sci. 103:3381-3391. https://doi.org/10.3168/jds.2019-17129.

Frankena, K., J. G. C. J. Somers, W. G. P. Schouten, J. V. van Stek, J. H. M. Metz, E. N. Stassen, and E. A. M. Graat. 2009. The effect of digital lesions and floor type on locomotion score in Dutch dairy cows. Prev. Vet. Med. 88:150-157. https://doi.org/10.1016/ j.prevetmed.2008.08.004.

Frössling, J., A. Rosander, C. Björkman, K. Näslund, and M. Pringle. 2018. Detection of Treponema phagedenis-like antibodies in serum and bulk milk from cows with and without digital dermatitis. J. Vet. Diagn. Invest. 30:86-92. https://doi.org/10.1177/ 1040638717733778 .

FVE. 2019. FVE position on welfare of dairy cows: Lameness. Accessed Sept. 22, 2020. https://www.fve.org/publications/fve-position-on -welfare-of-dairy-cows-lameness/.

Gomez, A., K. S. Anklam, N. B. Cook, J. Rieman, K. A. Dunbar, K. E. Cooley, M. T. Socha, and D. Döpfer. 2014. Immune response against Treponema spp. and ELISA detection of digital dermatitis. J. Dairy Sci. 97:4864-4875. https://doi.org/10.3168/jds.2013 -7616 .

Holzhauer, M., C. Hardenberg, C. J. M. Bartels, and K. Frankena. 2006. Herd- and cow-level prevalence of digital dermatitis in the Netherlands and associated risk factors. J. Dairy Sci. 89:580-588. https://doi.org/10.3168/jds.S0022-0302(06)72121-X.

Klitgaard, K., A. F. Bretó, M. Boye, and T. K. Jensen. 2013. Targeting the treponemal microbiome of digital dermatitis infections by high-resolution phylogenetic analyses and comparison with fluorescent in situ hybridization. J. Clin. Microbiol. 51:2212-2219. https: //doi.org/10.1128/JCM.00320-13.

Krull, A. C., J. K. Shearer, P. J. Gorden, V. L. Cooper, G. J. Phillips, and P. J. Plummer. 2014. Deep sequencing analysis reveals temporal microbiota changes associated with development of bovine digital dermatitis. Infect. Immun. 82:3359-3373. https://doi.org/ 10.1128/IAI.02077-14.

Moe, K. K., T. Yano, K. Misumi, C. Kubota, W. Yamazaki, M. Muguruma, and N. Misawa. 2010. Analysis of the IgG immune response to Treponema phagedenis-like spirochetes in individual dairy cattle with papillomatous digital dermatitis. Clin. Vaccine Immunol. 17:376-383. https://doi.org/10.1128/CVI.00464-09.

Oliveira, V. H. S., J. T. Sørensen, and P. T. Thomsen. 2017a. Associations between biosecurity practices and bovine digital dermatitis in Danish dairy herds. J. Dairy Sci. 100:8398-8408. https://doi.org/ 10.3168/jds.2017-12815.

Oliveira, V. H. S., J. T. Sørensen, and P. T. Thomsen. 2017b. Can digital dermatitis be detected in the milking parlor without washing cows' feet? Res. Vet. Sci. 115:325-326. https://doi.org/10.1016/j .rvsc.2017.06.017.
Potterton, S. L., N. J. Bell, H. R. Whay, E. A. Berry, O. C. D. Atkinson, R. S. Dean, D. C. J. Main, and J. N. Huxley. 2012. A descriptive review of the peer and non-peer reviewed literature on the treatment and prevention of foot lameness in cattle published between 2000 and 2011. Vet. J. 193:612-616. https://doi.org/10 $.1016 / j . t v j 1.2012 .06 .040$.

R Core Team. 2018. R: A language and environment for statistical computing. R Foundation for Statistical Computing, Vienna, Austria.

Relun, A., R. Guatteo, P. Roussel, and N. Bareille. 2011. A simple method to score digital dermatitis in dairy cows in the milking parlor. J. Dairy Sci. 94:5424-5434. https://doi.org/10.3168/jds .2010-4054.

Rodriguez-Lainz, A., P. Melendez-Retamal, D. W. Hird, and D. H. Read. 1998. Papillomatous digital dermatitis in Chilean dairies and evaluation of a screening method. Prev. Vet. Med. 37:197-207. https://doi.org/10.1016/S0167-5877(98)00091-9.

Rosander, A., B. Guss, L. Frykberg, C. Björkman, K. Näslund, and M. Pringle. 2011. Identification of immunogenic proteins in Treponema phagedenis-like strain V1 from digital dermatitis lesions by phage display. Vet. Microbiol. 153:315-322. https://doi.org/10 .1016/j.vetmic.2011.06.005.

Sobhy, N. M., Y. S. Mahmmod, W. Refaai, and A. Awad. 2020. Molecular detection of Treponema species organisms in foremilk and udder cleft skin of dairy cows with digital dermatitis. Trop. Anim. Health Prod. https://doi.org/10.1007/s11250-019-02072-0.

Solano, L., H. W. Barkema, C. Jacobs, and K. Orsel. 2017. Validation of the M-stage scoring system for digital dermatitis on dairy cows in the milking parlor. J. Dairy Sci. 100:1592-1603. https:// doi.org/10.3168/jds.2016-11365.

Solano, L., H. W. Barkema, S. Mason, E. A. Pajor, S. J. LeBlanc, and K. Orsel. 2016. Prevalence and distribution of foot lesions in dairy cattle in Alberta, Canada. J. Dairy Sci. 99:6828-6841. https://doi .org/10.3168/jds.2016-10941.

Sprecher, D. J., D. Hostetler, and J. B. Kaneene. 1997. A Lameness scoring system that uses posture and gait to predict dairy cattle reproductive performance. Theriogenology 47:1179-1187. https:// doi.org/10.1016/S0093-691X(97)00098-8.

Stokes, J. E., K. A. Leach, D. C. J. Main, and H. R. Whay. 2012. The reliability of detecting digital dermatitis in the milking parlour. Vet. J. 193:679-684. https://doi.org/10.1016/j.tvjl.2012.06.053.

Thomsen, P. T., I. C. Klaas, and K. Bach. 2008. Short communication: Scoring of digital dermatitis during milking as an alternative to scoring in a hoof trimming chute. J. Dairy Sci. 91:4679-4682. https://doi.org/10.3168/jds.2008-1342.

Tremblay, M., T. Bennett, and D. Döpfer. 2016. The DD Check App for prevention and control of digital dermatitis in dairy herds. Prev. Vet. Med. 132:1-13. https://doi.org/10.1016/j.prevetmed 2016.07.016.

Vanhoudt, A., D. A. Yang, T. Armstrong, J. N. Huxley, R. A. Laven, A. D. Manning, R. F. Newsome, M. Nielen, T. van Werven, and N. J. Bell. 2019. Interobserver agreement of digital dermatitis Mscores for photographs of the hind feet of standing dairy cattle. J. Dairy Sci. 102:5466-5474. https://doi.org/10.3168/jds.2018-15644.

Vink, W. D., G. Jones, W. O. Johnson, J. Brown, I. Demirkan, S. D. Carter, and N. P. French. 2009. Diagnostic assessment without cut-offs: Application of serology for the modelling of bovine digital dermatitis infection. Prev. Vet. Med. 92:235-248. https://doi.org/ 10.1016/j.prevetmed.2009.08.018.

Yang, D. A., and R. A. Laven. 2019. Detecting bovine digital dermatitis in the milking parlour: To wash or not to wash, a Bayesian superpopulation approach. Vet. J. 247:38-43. https://doi.org/10 $.1016 / j . t v j 1.2019 .02 .011$.

\section{ORCIDS}

T. Aubineau () https://orcid.org/0000-0002-7242-2849

A. Relun (ㄴ) https://orcid.org/0000-0001-7304-3616

B. Gentin (๑) https://orcid.org/0000-0002-1456-0389

R. Guatteo @ https://orcid.org/0000-0002-6658-522X 